\title{
Using a phone-based learning tool as an instructional resource for initial literacy learning in rural African families
}

\begin{tabular}{|c|c|}
\hline \multicolumn{2}{|c|}{$\begin{array}{l}\text { Authors: } \\
\text { Jacob C. Nshimbi }{ }^{1} \text { (D) } \\
\text { Robert Serpell }{ }^{2,3} \text { (D) } \\
\text { Jari Westerholm }{ }^{4} \text { (D) }\end{array}$} \\
\hline \multicolumn{2}{|c|}{$\begin{array}{l}\text { Affiliations: } \\
{ }^{1} \text { Department of Psychology, } \\
\text { School of Humanities and } \\
\text { Social Sciences, University of } \\
\text { Zambia, Lusaka, Zambia }\end{array}$} \\
\hline \multicolumn{2}{|c|}{$\begin{array}{l}{ }^{2} \text { Centre for the Promotion of } \\
\text { Literacy in Sub-Saharan Africa } \\
\text { (CAPOLSA), Lusaka, Zambia }\end{array}$} \\
\hline \multicolumn{2}{|c|}{$\begin{array}{l}{ }^{3} \text { Department of Psychology, } \\
\text { University of Zambia, Lusaka, } \\
\text { Zambia }\end{array}$} \\
\hline \multicolumn{2}{|c|}{$\begin{array}{l}{ }^{4} \text { Niilo Mäki Institute, } \\
\text { University of Jyväskylä, } \\
\text { Jyväskylä, Finland }\end{array}$} \\
\hline \multicolumn{2}{|c|}{$\begin{array}{l}\text { Corresponding author: } \\
\text { Jacob Nshimbi, } \\
\text { jcnshimbi@gmail.com }\end{array}$} \\
\hline \multicolumn{2}{|c|}{$\begin{array}{l}\text { Dates: } \\
\text { Received: } 06 \text { Feb. } 2018 \\
\text { Accepted: } 02 \text { Nov. } 2019 \\
\text { Published: } 27 \text { Feb. } 2020\end{array}$} \\
\hline \multicolumn{2}{|c|}{$\begin{array}{l}\text { How to cite this article: } \\
\text { Nshimbi, J.C., Serpell, R. \& } \\
\text { Westerholm, J., 2020, 'Using } \\
\text { a phone-based learning tool } \\
\text { as an instructional resource } \\
\text { for initial literacy learning } \\
\text { in rural African families', } \\
\text { South African Journal of } \\
\text { Childhood Education 10(1), } \\
\text { a620. https://doi.org/ } \\
\text { 10.4102/sajce.v10i1.620 }\end{array}$} \\
\hline \multicolumn{2}{|c|}{$\begin{array}{l}\text { Copyright: } \\
\text { (C) 2020. The Authors. } \\
\text { Licensee: AOSIS. This wor } \\
\text { is licensed under the } \\
\text { Creative Commons } \\
\text { Attribution License. }\end{array}$} \\
\hline \multicolumn{2}{|l|}{ Read online: } \\
\hline aripi: & $\begin{array}{l}\text { Scan this QR } \\
\text { code with your } \\
\text { smart phone or } \\
\text { mobile device } \\
\text { to read online. }\end{array}$ \\
\hline
\end{tabular}

Background: Despite increased enrolments at primary schools in Zambia, more than half of the children in Grades 1-4 are unable to meet the required minimum standards for literacy.

Aim: The study set out to examine the effects of using a phone-based mobile literacy game (Graphogame) to improve literacy skills in children and adults in rural family settings.

Setting: The study was conducted in the Katete District, a rural town in the eastern province of Zambia.

Methods: Participants were 73 Grade 2 learners (52\% boys, mean age 9 years and $48 \%$ girls, mean age 10 years) and 37 parents (mean age 36 years). Three literacy tests, measuring lettersound identification, phonological awareness, spelling competence and word recognition, were administered to both the children and parents. Parents also reported on their level of education, familiarity with smart phone use, availability of home reading materials and home literacy activities.

Results: The findings showed that children who were exposed to the Graphogame performed better than the control group on all literacy measures. Furthermore, parent's performance on the tests improved after the intervention.

Conclusion: The findings suggest that technology can improve literacy skills in both children and adults in rural areas of Zambia.

Keywords: Graphogame; early literacy skills; rural family setting; home literacy environment; Zambia.

\section{Introduction}

The Africa Progress Panel (2012) report points out that despite the 90\% primary-schooling system in Zambia, half of the children in lower grades (1-4) are unable to meet basic literacy standards. According to Brombacher et al. (2015), results of the Grade 2 National Assessment Survey of Learning Achievement show that the situation has not improved much (Sampa 2016). This is far from the 'aspirations of being educated for life or completing basic education' (World Vision International 2012). The United Nations Educational, Scientific and Cultural Organisation (UNESCO) has called for methodologically sound research efforts on mother tongue-based early education practices (Ball 2011). Without such efforts it will be difficult to attain the 'target of increasing the percentage of children who can read by age of 11 years' (World Vision International 2012).

A longitudinal study of difficulties that dyslexic children in Finland face in the acquisition of early literacy revealed that intensive instruction in letter-sound association can greatly enhance a child's ability to accurately acquire decoding skills, which are a prerequisite for initial literacy (Lyytinen et al. 2008). This study ultimately led to the development of a computer-based instructional phonics game (Graphogame) to aid not only all children but also those with dyslexia. The effectiveness of this game has been empirically validated in Finland (Lyytinen et al. 2008). In addition, findings by Jere-Folotiya et al. (2014) from the Reading Support for Zambian Children (RESUZ) study, on the effect of using mobile literacy game to improve literacy, indicated that both teachers and pupils in a representative sample of Grade 1 classes (573 leaners) in Lusaka appreciated the support that the game provides in learning letter-sound associations, a key aspect of initial literacy acquisition.

Jere-Folotiya et al. (2014) found that the ciNyanja version of Graphogame mounted on hand-held mobile phones was an effective resource for supporting initial literacy learning by Zambian 
children enrolled in Grade 1. This study was conducted in 42 urban government schools in Lusaka. The smart phones loaded with Graphogame were loaned to the participating children to play the game under the supervision of University of Zambia (UNZA) undergraduate students. Further research and development is now under way under the auspices of UNZA's Centre for Promotion of Literacy in Sub-Saharan Africa (CAPOLSA), with a view to making Graphogame and other literacy learning resources available as widely as possible throughout Zambia (Ojanen et al. 2015; Serpell 2014).

Research has shown that the process of literacy acquisition starts way before a child enters formal schooling (Storch \& Whitehurst 2001; Van Steensel 2006; Weigel, Martin \& Bennett 2006). It is in the home and the immediate environment that a child is first socialised in the world of literacy and for some children the home provides a platform on which they first encounter written material (Chansa-Kabali \& Westerholm 2014; Snow, Burns \& Griffin 1998; Snow, Tabors \& Dickinson 2001). The process of language learning by children starts in the home with the help of parents and other members of the family. According to Chomsky (1986), this process is biologically determined because children are born with specific linguistic knowledge. Bruner (1983), on the other hand, emphasises that social context in which language development takes place is also important. Learning to read, however, requires a child to learn to recognise letters and their corresponding sounds. For children living in home environments rich in literacy activities and resources, initial literacy may be mastered with little deliberate instructions (Chazan-Cohen et al. 2009; Jung 2016; Serpell, Baker \& Sonnenschein 2005), but for children in low-literacy family environments, deliberate and carefully planned sessions of instructions may serve a critical function to act as a catalyst for them to acquire literacy.

In Zambia, like in most African countries, literacy is the key to achieve success in school. According to the National Literacy Framework (MESVTEE 2013:6), '... reading is a foundational skill for learning across subject areas'. The acquisition of reading skills therefore promotes independent learning in pupils and reduces school dropout rates. Literacy and, by extension, success in school equip individuals to participate fully in the social, economic, cultural and political life. The cognitive outcomes of literacy should be understood in the social cultural context in which they occur. Serpell (1993) argues that ideally when children become literate, they should acquire a sense of how their knowledge relates to others in their society, and more importantly their society provides a cultural framework in which their acquired skills can be put to meaningful use.

Social class has an impact on the quality of support children are provided with at home for their initial literacy learning. However, Serpell et al. (2005) have argued that socioeconomic factors do not directly impact literacy development. Rather it is the 'intimate culture' of the family that strongly supports literacy development mediating the influence of social economic status. This intimate culture involves parental beliefs, everyday interactions of parents with their children and recurrent activities that parents and children engage in with regard to reading.

A study conducted amongst Grade 1 urban children in Zambia by Chansa-Kabali et al. (2014) showed that children experience literacy in different forms. The study assessed factors such as parental reading attitude and family literacy activities, and looked at children's socio-economic status from two perspectives: parental education and family possessions. The results showed that of the four factors assessed (parental reading attitude, family literacy activities, parental education and family possessions), only family literacy activities and parental reading attitudes (i.e. the intimate culture of the family) explained much more variance in the measures of reading skills than material wealth.

The involvement of parents in their child's literacy learning is a strong catalyst for language and emergent literacy skills (Anderson, Anderson, Friedrich \& Kim 2010; Bus, Van Ijzendoorn \& Pelligrini 1995; Timmons \& Pelletier 2015). This study has adopted the concepts espoused in New Literacy Studies and has viewed literacy as a social practice (Street 2003), which is firmly fixed within specific cultural contexts and mediated by particular cultural tools (Gutiérrez 2002). The notion espoused here is that language learning is influenced by the social contexts in which children (and adults) are immersed and that they draw on a range of mediational tools in the construction of meaning. Acquisition of literacy, therefore, can be a joint accomplishment which takes place in social interactions as people jointly perform social and cultural tasks. Literacy is not simply an individual cognitive activity, but a communicative tool for different social groups. It is socially constituted and given meaning by its location in societally, historically generated systems of activity and does not derive its meaning from individual intentions but from mutually constituted relations between activity systems and the persons acting (Cole \& Engestrom 1983; Salomon 1993). In agreeing with this view, our study collected systematic detailed information about the proximal environment in the village homes of children's initial encounters with literacy practices and technology.

The RESUZ study mentioned earlier showed that it is possible to use technology such as smart phones to improve literacy amongst pupils in low-income urban schools in Zambia. Other studies in Africa have also looked at the effectiveness of using mobile phones as an educational tool (Aker, Ksoll \& Lybbert 2010). However, these studies and many others have mainly been focused on (1) children in urban areas, (2) children with the exclusion of their parents or (3) children's literacy acquisition in formalised learning environments like schools (Matafwali 2010; Ojanen 2007; Tambulukani \& Bus 2012). However, the majority of African and indeed Zambian children experience their first encounter with the practices and technology of literacy in rural family 
settings where the family and community are the main agents of literacy socialisation, rather than professionally trained teachers.

This study was therefore designed to (1) shift the focus from urban settings and low-income urban schools to rural schools and (2) concentrate on non-school informal literacy experiences with mobile phones in home settings. The study hypothesised that children exposed to Graphogame would show a greater increase in scores on literacy tests compared with those not exposed to Graphogame.

Graphogame is a game-based literacy technological innovation that acts as a catalyst for early literacy learners. In the initial literacy learning phase of the programme, the focus is on decoding skills (by mastery of letter-sound correspondence rules).

\section{Methodology}

This study was part of a larger project called Piloting Efficient Distribution of the Graphogame (PED-GG) to children in rural areas in Zambia. The aim of the study was to document the efficiency of Graphogame-based reading support if distributed via teachers and homes. The study was conducted in schools in three districts of Eastern Province. The participants were Grade 2 learners from selected schools in Katete, Chipata and Lundazi and their parents or guardians. The schools from which the participants were picked were a sample of schools in which Zambia Read to Succeed (RTS) Project had been conducting Early Grade Reading Assessment (EGRA) in the Eastern Province. Eight pupils were selected from each school. These eight pupils (four girls and four boys) were selected using a systematic random sampling. Based on these criteria, 24 girls and 24 boys were picked from each of the six schools in each of the three districts, bringing the total number to 48 participants per district. This brought the total number of children in the study to 144 .

\section{Research design}

This was an intervention study (with a pre-test and post-test design) in which a representative sample of Grade 2 learners attending public primary schools and residing in low-literacy, low-income villages in a rural district of Zambia were loaned GG mounted on a cellphone to play at home under the general supervision of their parents.

The study was designed in such a way that participants from Katete District who had been part of the PED-GG and a comparative randomly selected sample of the children's classmates would be followed in their homes for further assessments and intervention. Katete District was picked because the version of Graphogame on the phone was in ciNyanja, the local language most widely used in homes and in children's play; furthermore, all the measures used were in ciNyanja (it is worth noting that the language called ciNyanja is known locally as ciCewa).

\section{Study site}

This study was conducted in Katete District of the Eastern Province of Zambia in the communities surrounding the following schools: Mkangazi, Mwaziputa, Chimbundire, Chiwuyu, Katiula and Mtetezi. Katete is $490 \mathrm{~km}$ east of the capital city Lusaka; it is a rural town with a population estimated to be about 190 000, with the majority (about 88\%) living in surrounding villages. The nearest school to the town amongst the research schools is Mwaziputa and is $39 \mathrm{~km}$ away. The people in this area practise subsistence agriculture, raising a few animals like cattle, goats and chickens and growing crops like maize, groundnuts, bananas and cotton. Fifty per cent of the adults in this area are not able to read, and there are no public libraries or any amenities to promote literacy acquisition.

\section{Participants}

Of the 96 learners and parents who were contacted, 73 stated that they were available and were recruited to participate in this study. The 73 learners with boys at $52 \%$ and girls at $48 \%$ (mean age of boys $=9.7$ years, standard deviation $[\mathrm{SD}]=1.2$; mean age of girls $=10.2$ years, $\mathrm{SD}=1.3$ ) comprised 45 children in the intervention group and 28 in the control group.

All the participants were assessed before and after the intervention. The intervention group were included in the study on the condition that they had participated in PED-GG project. During this study learners in the intervention group were exposed to Graphogame, with a combined total of 12 playing days and a combined maximum of $6 \mathrm{~h}$ playing time. The control group were classmates of the children in the intervention group and had previously participated in EGRA testing by RTS. However, these children had no prior exposure to Graphogame.

\section{Measures}

All the measures were in ciNyanja, the language most widely used in homes and in children's play, as confirmed by preliminary interviews with the children and their parents. It is also used as a language of instruction in public primary schools in the study area.

\section{Group test battery}

This test was designed by Kalanje (2011) as a group-based screening tool for identifying first graders at risk of reading and writing difficulties. The group test battery includes measures of word recognition, letter recognition and phonological awareness. Measures of word recognition include three subscales: word-picture, picture-word and wordchain. Measures of letter recognition include two subscales: picture-letter and letter-picture. Measures of phonological awareness include two subscales: initial sound and spelling.

It was administered in Kiswahili to 337 Grade 1 children from different schools in Tanzania and produced a reliability score of 0.91 to 0.97 (Cronbach's alpha) in all scales (Kalanje 2011). 
For the purpose of this study, the group test battery was translated from Kiswahili to ciNyanja. The test was administered to both groups of children and parents of the Graphogame players. The purpose of this test was to measure participants' ability in word recognition, letter recognition and phonological awareness. The test has five sections: section 1 has a series of four pictures with a target word identifying one of the pictures; the child is supposed to pick the picture represented by the word. The score ranges from 0 to 10 . Sections 2 and 3 have a target picture and a series of four words placed after it. Learners are supposed to pick the word which represents the picture; the score for each of these sections ranges from 0 to 10 . Sections 4 and 5 have a letter with a series of four pictures; the learner is supposed to select a picture with a name that starts with the given letter. These two sections have scores ranging from 0 to 12 . The total possible maximum score for the group test battery is 54 .

\section{Spelling test (decoding competency)}

This test was developed by the RESUZ team comprising JereFolotiya, Chansa-Kabali, Yalukanda, Sampa and Munachaka from the University of Zambia in collaboration with Lyytinen and Ojanen from the University of Jyvaskyla in 2011. It is an individually administered test of early graders' competence in spelling ciNyanja.

This test was administered to a sample of 43 Grade 1 learners in an urban school in Lusaka and had a test-retest reliability of $r=0.82$ (Jere-Folotiya et al. 2014). It consists of 20 dictated items (in this study the test was dictated by the research assistant who was a native speaker of the language). Phonemes, syllables and words are presented in this order and are arranged in order of increasing difficulty. The leaner is required to choose from four possible answers and underline the correct response. A score of 1 was given for every correct response and 0 for every incorrect response. The range of possible scores on this test was 0-20.

\section{Zambia Assessment of Early Literacy Abilities}

The Zambia Assessment of Early Literacy Abilities (ZAELA) (Banda 2012) is a group-administered reading and writing assessment tool that measures literacy skills of Grades 1 and 2 Zambian pupils. It is an early grade local language reading and writing assessment tool that measures letter-sound identification and phonological awareness of early literacy learners. Zambia Assessment of Early Literacy Abilities was trialled on 2500 Grades 1 and 2 pupils in Petauke and Katete districts of eastern Zambia and had a reliability score of 0.74 (Cronbach's alpha). The test has four sections: section A assesses writing skills, section B assesses phonological awareness, section $C$ assesses word recognition and section $\mathrm{D}$ assesses reading fluency, and these sections can be administered independent of each other. For this study, two sections of the ZAELA were used: section B (phonological awareness) and section $\mathrm{C}$ (word recognition). Section $\mathrm{B}$ has subsections which require learners to (1) identify and count syllables in names of a given picture, (2) recognise initial and final sounds in names of a given picture and (3) divide words of a picture into syllables. Section $C$ requires children to (1) divide words into individual components. Three pictures are presented to a learner and the names of the picture are written below the pictures as one word; the learner is required to divide this word into individual names by identifying the names that correspond to each picture by drawing a slash where one name ends and another begins, and (2) to identify a word from a given list. There are three items in each row and there are five rows. The possible scores on ZAELA in this study ranged from 0 to 51 .

\section{Graphogame intervention}

Nokia X cell phones, mounted with Graphogame (a phonebased computer game), were distributed to learner-parent dyads to play for a period of 6 weeks. The distribution of the phones was done by teachers of the learners in each school. These teachers had received Graphogame training in a 2-day workshop during the PED-GG project. The training involved orienting the teachers to create player accounts for children, send logs to the server and access other Graphogame-related materials (such as stories and books) on the phone. Because the phones were to be used in the learners' homes, the teachers oriented the parents and their children on how to use the phones. The parents were instructed to ensure that the children use their own player account and play the game in sessions of 20-30 $\mathrm{min}$, with a maximum of five sessions per day. The children took the phones to the teacher once a week for the purpose of sending game logs and to address any challenges encountered in the course of playing the game. In some cases where the family had no access to electricity, the phones had to be taken to the school for charging.

The main challenge that teachers frequently reported was the deletion of player accounts by both children and their parents and in such cases the accounts had to be retrieved from the server. Because of this challenge, exposure time for one child was not available although he had played the game. The mean exposure time for 44 learners was $M=7.9 \mathrm{~h}$ and SD of 5.5 , with a maximum playing time of $21: 27 \mathrm{~h}$ and a minimum of $59 \mathrm{~min}$.

\section{Family literacy environment}

A structured questionnaire was used to quantitatively assess the family and home literacy environment of the participants; the questionnaire specifically addressed parents' academic qualifications, familiarity with smart phone use, availability of home reading materials and home literacy activities. Four ethno-theory questions assessing home literacy activities asked parents what they believed was the best way of teaching their children to read. Some of the items in the questionnaire were adapted from the Home Literacy Questionnaire (HLQ) designed by Chansa-Kabali and used in her 2014 study (Chansa-Kabali \& Westerholm 2014). 
In addition to the questionnaires, focus group discussions were held at each of the schools attended by the learners during the pre-testing phase and the post-testing phase. The members of the groups were mothers (and one father) of the learners who were in the intervention group. The discussions were semi-structured and were led by a research assistant. The guiding topics for the discussions were literacy-related activities that the parents engaged in for the benefit of their children.

\section{Testing procedure}

Assessment of both learners' literacy competence was done at the respective schools attended by each group of children. Written consent of the children to participate in the study was obtained in the initial PED-GG pilot study from both the school and the parents. Additional consent was obtained orally for the current study from the parents (for children in the intervention group) and from the school (for the learners in the comparison group).

All the assessments were done at the individual schools of the participants. They were administered by one of the authors and the learners' teacher (at each school) who were recruited and trained as research assistants. To ensure that the participants did not copy from each other, large classrooms were used and each participant sat at a desk alone, and the desks were arranged at least a meter apart on all sides.

For the group test battery, instructions for the test were read aloud by the assessor (who is a fluent speaker of the language) and an example was given for each section. Then the participants were asked to answer that section by underlining the correct item, and this procedure was repeated for each section until all sections were completed.

The decoding competency test (spelling) was administered as an individual test. The assessors, who were also native speakers of the language, dictated to the participants the 20 items, one at a time, repeating each item three times. Each participant was required to underline the correct response selected from four options listed in random order on a printed answer sheet.

For the ZAELA, a testing procedure similar to that used in the battery test was used. After giving an example for B1, the assessor read the name of the item in the picture three times and asked the respondents to write the number of syllables they heard below that particular picture. There were a total of 21 pictures. For B2, the assessor read the name of the picture three times and asked the respondents to write the initial or final sound for that particular picture. There were five rows of pictures with three items in each row for initial sound and five rows of pictures with three items for final sound. Only one picture was read out from each row, resulting in a maximum score of 10. For B3, a list of five pictures was given and numbers 1-6 were written beside the picture the respondent was supposed to circle the number which corresponded to the syllables found in the name of each given picture. The assessor read the name of the picture three times and allowed the respondents to answer until all the five items were done; the maximum score was 5 .

For $\mathrm{C} 1$, the assessor read out the names of the three pictures in a set, one at a time and repeating three times; then the respondents were asked to divide the given word below the set of pictures. The combined picture names were jumbled. For C2, the assessor read out one word from each row three times and asked the respondents to identify and underline that word from the given list of three pictures in a row. There were five rows, giving a maximum score of 5; the total score for this section was 15. And the maximum total score for the test (ZAELA) was 51.

\section{Data analysis}

The focus of all the analyses was on the effect of playing Graphogame on the difference between pre-test and post-test results. The following hypothesis was tested:

Participants who played the GG would show a greater increase in scores on each of the 3 literacy tests (from pre-test to post-test) than those participants that did not play the game.

To test the hypothesis, a repeated measures multivariate analysis of variance (rm-MANOVA) was used to compare the learners who played Graphogame with those learners who did not play the game, with group membership entered as a between-subject factor, while the time of testing (pre-test and post-test) and the three measured variables were entered as within-subject factors using version 21 of Statistical Package for Social Sciences (SPSS).

Group discussions with parents were analysed by comparing and categorising common themes in the discussion about the importance of learning how to read for children and whether the parents engaged in any form of reading with their children. Specific information related to individual parents' views on these two points were structured in terms of common patterns and inter-relations.

The family literacy environment questionnaire was analysed using descriptive analyses in the form of percentages.

\section{Ethical considerations}

The involvement of pupils, teachers and all caregivers in this study was done with total observance of informed consent and high confidentiality of the information maintained.

\section{Results}

Before the final analysis, a missing data analysis was conducted because the final research data had some missing values. The rate of missing values in learners' data varied from pre-test $(0 \%-1.4 \%)$ to post-test $(8.2 \%)$, which is low in 
pre-test but not in post-test. In post-tests, the rate of missing values was double within the girls $(11.4 \%)$ compared with the boys $(5.3 \%)$. Little's missing completely at random (MCAR) test in learners' data using the literacy summary variables $\left(\chi^{2}=15265, d f=13\right.$, Significance [Sig.] $\left.=0.291\right)$ revealed that the rate of missing information values was completely at random and it allowed to have unbiased estimates when using listwise deletion as a way to handle missing data like rm-MANOVA automatically does.

Prior to conducting an rm-MANOVA, a series of Pearson correlations were performed between all the dependent variables to test the assumption that the dependent variables would be correlated with each other (Meyers, Gamst \& Guarino 2006). A meaningful pattern of correlations was observed pre-test and post-test, suggesting the appropriateness of a MANOVA (Appendix 1).

Average group-wise performances on all the measures were compared for the pre- and post-tests for all the children (i.e. children who were exposed to Graphogame and those who were not exposed). The results (Appendix 2) indicated that the mean scores on the post-tests were higher than the pretests in the GG player group, whereas it was lower in the case of the control group. Therefore, the data were subjected to further analysis to determine if these differences were statistically significant.

In rm-MANOVA, a statistically significant interaction effect was found between time of testing (pre-test and post-test) and group membership (GG players and control): Pillai's trace $=0.218, F(3,61)=5.664, p=0.002$, partial $\eta^{2}=0.218$. Univariate test results revealed that the interaction was also significant in all three research measures. Further analysis using simple effects was done to determine what contributed to this significant interaction.

Simple effects pairwise comparison (Table 1) shows that the performance of the group that was exposed to GG was significantly different between the two time points in test battery and dictation (but not in ZAELA), with corresponding effect sizes being large and medium, respectively. However, there was no significant difference in performance for the group that was not exposed to GG in all tests. All the $p$-values were corrected against the type I error (family-wise error rate [FWER]) with the Holm's procedure.

Table 2 shows that there was no significant difference between the marginal means of two groups at pre-test; however, significant differences were recorded at post-test. But after conducting FWER analysis with Holm's procedure, the difference was only recorded in battery post-measurements with large effect. The estimated marginal means (Appendices 3-5) of the two groups for the three measures were similar at pre-test but increased for the group that played GG at posttest. It is worth noting, however, that part of the postmeasurement effect came from the decrease of the control group measurement.

\section{Family literacy environment analysis}

Analysis of the family literacy environment indicated that none of the children who participated in this study had attended nursery school. Fifty-five per cent of their mothers had never attended school, while $36 \%$ had attended primary school, only $6 \%$ had attended secondary school and $3 \%$ did not give a response. On the question of experience with smart phones, $78 \%$ of the mothers indicated

TABLE 1: Simple effects pairwise comparison and mean difference in performance by groups on literacy tests.

\begin{tabular}{|c|c|c|c|c|c|c|c|c|}
\hline \multirow[t]{2}{*}{ Measure } & \multirow[t]{2}{*}{ Group } & \multirow[t]{2}{*}{ Time } & \multirow{2}{*}{$\begin{array}{l}\text { Mean diff. } \\
\text { (time) }\end{array}$} & \multirow[t]{2}{*}{ SE } & \multirow[t]{2}{*}{ Sig. $\dagger$} & \multirow{2}{*}{$d_{\text {cohen }} *$} & \multicolumn{2}{|c|}{$95 \% \mathrm{Cl}$} \\
\hline & & & & & & & Lower bound & Upper bound \\
\hline \multirow[t]{2}{*}{ ZAELA } & GG player & Pre-Post & -4.34 & 1.98 & 0.128 & -0.35 & -8.29 & -0.39 \\
\hline & Non-GG player & Pre - Post & 4.30 & 2.59 & 0.306 & 0.385 & -0.877 & 9.46 \\
\hline \multirow[t]{2}{*}{ Battery } & GG player & Pre-Post & -11.02 & 1.99 & 0.006 & -0.946 & -15.01 & -7.04 \\
\hline & Non-GG player & Pre - Post & 0.71 & 2.61 & 0.976 & 0.064 & -4.50 & 5.92 \\
\hline \multirow[t]{2}{*}{ Dictation } & GG player & Pre-Post & -3.00 & 0.96 & 0.015 & -0.54 & -4.92 & -1.08 \\
\hline & Non-GG player & Pre-Post & 0.88 & 1.25 & 0.976 & 0.16 & -1.63 & 3.38 \\
\hline
\end{tabular}

Source: Adapted from Holm, S., 1979, 'A simple sequentially rejective multiple test procedure', Scandinavian Journal of Statistics 62(2), 65-70.

$\mathrm{SE}$, standard error; $\mathrm{Cl}$, confidence interval; GG, Graphogame; diff., mean difference; Sig., significance.

$\dagger$, Adjustment for multiple comparisons: Holm (1979).

¥. Calculated noting that measurements were not independent using equation 4 from https://www.psychometrica.de/effect_size.html.

TABLE 2: Simple effects pairwise comparison and mean difference in performance at pre-test and post-test.

\begin{tabular}{|c|c|c|c|c|c|c|c|c|}
\hline \multirow[t]{2}{*}{ Measure } & \multirow[t]{2}{*}{ Time } & \multirow[t]{2}{*}{ Groups } & \multirow{2}{*}{$\begin{array}{l}\text { Mean diff. } \\
\text { (groups) }\end{array}$} & \multirow[t]{2}{*}{ SE } & \multirow[t]{2}{*}{ Sig. $\dagger$} & \multirow[t]{2}{*}{$d_{\text {cohen }} *$} & \multicolumn{2}{|c|}{$95 \% \mathrm{Cl}$} \\
\hline & & & & & & & Lower bound & Upper bound \\
\hline \multirow[t]{2}{*}{ ZAELA } & Pre & GG player-Non-GG player & -1.35 & 2.89 & 1.0 & -0.12 & -7.12 & 4.42 \\
\hline & Post & GG player-Non-GG player & 7.28 & 3.24 & 0.140 & 0.578 & 0.81 & 13.76 \\
\hline \multirow[t]{2}{*}{ Battery } & Pre & GG player - Non-GG player & -2.19 & 3.01 & 1.0 & -0.188 & -8.19 & 3.80 \\
\hline & Post & GG player- Non-GG player & 9.54 & 2.87 & 0.006 & 0.855 & 3.81 & 15.27 \\
\hline Dictation & Pre & GG player - Non-GG player & -1.04 & 1.52 & 1.0 & -0.176 & -4.08 & 1.99 \\
\hline
\end{tabular}

Source: Adapted from Holm, S., 1979, 'A simple sequentially rejective multiple test procedure', Scandinavian Journal of Statistics 62(2), 65-70.

$\mathrm{SE}$, standard error; $\mathrm{Cl}$, confidence interval; GG, Graphogame; diff., mean difference; Sig., significance.

$\dagger$, Adjustment for multiple comparisons: Holm (1979).

$\$$, Calculated noting that measurements were independent using equation 4 from https://www.psychometrica.de/effect_size.html. 
that neither they nor any of their family members had experience with any sort of phone.

In terms of availability of reading materials in the home, $68 \%$ mentioned that they did not have any sort of reading materials in their homes, while $17 \%$ stated that they only had school books for children to read and $2 \%$ said that they had supplementary readers. For those who showed that they had some form of reading materials in the house, $61 \%$ said that all the reading materials were in the form of religious materials (such as the Bible). Eighty-eight per cent, however, indicated that they developed more interest in reading after playing Graphogame.

Analysis of the ethno-theory questions to mothers on what they thought was the right way to help their children to learn how to read indicated that $46 \%$ thought reading to the child was the right way, $31 \%$ said helping them to learn letters by sounding the alphabet, $12 \%$ said by helping them identify simple words and $48 \%$ thought the right way was to help children connect simple sound to their corresponding letters.

Finally, the parents were asked to indicate who they thought was responsible for teaching their children to learn how to read and prompted to indicate from three alternatives. Sixtythree per cent indicated that the teacher was solely responsible to teach reading to children, $59 \%$ indicated that the parent was responsible and only $8 \%$ thought that siblings were responsible for teaching children reading.

\section{Thematic analysis}

Group discussions with parents were analysed by comparing and categorising common themes in the discussion about the importance of learning how to read for both children and parents and whether the parents engaged in any form of reading themselves or with their children. Specific information related to individual parents' views on these two points were structured in terms of common patterns and inter-relations. One common pattern that was identified regarding the importance of acquiring reading skills was that it enhanced children's chances of finishing school, which would eventually lead them to find good jobs. Very few parents regarded reading as a skill that children needed for life; competence in reading was seen as a tool for success in school.

The discussion with the parents also revealed that prior to the exposure to GG nearly all of them did not engage in any form of literacy activities with their children even for the purpose of helping them with their homework; this task was usually delegated to an older sibling or any other older school-going child in the community. However, after playing GG the majority of the parents mentioned that their interest in reading improved and they even engaged in limited literacy activities with their children, such as playing the game together.

\section{Discussion}

This study provides a unique look into the effect of using a phone-based mobile literacy game (Graphogame) to improve literacy amongst pupils in rural schools and rural family settings. The findings revealed that there was a statistically significant interaction effect between group membership and time of testing (pre-test/post-test).

Furthermore, univariate tests showed that children who were exposed to the Graphogame performed better on all the measures than their classmates who did not receive any exposure to the literacy game.

Beyond the numbers, however, the findings have revealed that it is possible to use technology such as phones and computer-based literacy learning programmes in rural areas of Zambia. Furthermore, such technology can be used in children's home settings. This is of particular interest and importance because despite the best efforts by stakeholders to ensure that all children in Zambia acquire basic skills in literacy and hence stand a chance at completing basic education (NLF 2013; World Vision International 2012), many children, especially in rural areas, are still unable to acquire basic literacy skills required for success in school (Africa Progress Panel 2012; Brombacher et al. 2015). The results of this study, and also other studies conducted on children in urban areas of Zambia (Chansa-Kabali and Westerholm 2014; Jere-Folotiya et al. 2014), indicate that Graphogame can be used effectively to help in addressing some of the difficulties that lead to children not acquiring the expected literacy skills appropriate to their grade level. Graphogame training can also support both teachers and parents in providing a suitable environment for teaching children early literacy skills.

Learners in this study who were exposed to Graphogame showed improved performance in test scores after the exposure. Furthermore, these children performed better on literacy post-tests than their classmates who were not exposed to the literacy game. The multivariate interaction effect observed serves to support our hypothesis that the intervention group's experience of playing Graphogame in their homes, coupled with the normal literacy instruction at school, gave them an advantage over the control group, who were only exposed to classroom instruction. Part of this interaction effect could have come from the decreasing results of control group, but the simple effects analyses showed that the most important reason behind this multivariate interaction was the Graphogame groups' positive development in test battery and dictation measurements with corresponding large and medium effects.

As discussed earlier, the classroom learning conditions in rural areas are inadequate; pupils lack adequate material for literacy and, apart from the little time allocated to literacy on the time table, teachers are often ill equipped to competently teach literacy. Therefore, literacy interventions, such as the use of literacy tools, are particularly important for children in 
rural Zambia because interviews with parents in this study revealed that children's home environments are also not conducive for literacy learning. Successful use of the Graphogame by children in this study in their homes, in addition to the literacy learning they engage in at school, can be one of the solutions to the non-conducive and inadequate home literacy environments that many rural families encounter. Non-school, informal literacy exposure to such literacy-enhancing technology in home settings can make significant impact on teaching literacy skills to rural children.

Another related outcome of the study is the role that a school plays in the socialisation of children in a particular community. It is widely accepted that schools play an important role in imparting socialisation skills, especially literacy skills, to children in the community it serves. However, how this is done in practice is a source of concern to most communities, especially rural ones (Serpell 1997). This can be reflected by the discrepancy between what parents believe and what they actually do; when asked about who they thought was responsible for teaching children to read, $63 \%$ of parents answered that teachers were responsible and only $8 \%$ stated siblings (older brothers, sisters, cousins, etc.) were responsible; yet in the focus group discussions, they indicated that the task of helping children with homework and any reading activities is usually delegated to siblings or any other older school-going children in the community. A possible explanation for this discrepancy may lie in the belief that the communities' socialisation agenda is different from the schools' socialisation agenda.

Many rural parents believe that they are experts in the 'ways' of their communities and therefore it is their responsibility to impart these 'ways' to their children. From an early age children are taught the practices of their community, such as herding cattle, washing plates, agricultural skills and tending to the household by their parents and other adult members of their community. These interactions have potential linkages to literacy. But as Serpell (1997) and Clemensen (2010) point out, these skills that children bring with them to the classroom are largely ignored and considered as not being compatible with the school's agenda. This agenda is generally accepted as socialising children through language so that they could become useful members of a particular society. Unfortunately, teachers in Zambia may not fully understand or wrongly interpret this agenda and narrowly restrict it to equipping children with literacy skills for purposes of succeeding in school and ultimately raise their social status. These rural schools therefore fail to appreciate that as children enter school, their socialisation process has already begun at home and their task is to build upon it and utilise the skills that parents and the community have already equipped the children with (Serpell 1997). As a result of this failure, schools in rural areas present knowledge to the children that is at odds with their natural context and their everyday experiences.

In giving the task of helping the child with reading to older children, parents recognise that most of the things taught in school are not compatible with their existing context. They, therefore, consider themselves ill equipped to help their children with homework or reading, skills which they consider not to be congruent with the immediate need of equipping their children with the skills they need to survive in their immediate environment.

The older brother, cousin or sister is therefore considered to be more qualified to help the child with these seemingly alien 'ways'. What this study helped parents realise (to a limited extent) is that learning to read is not only for the purpose of succeeding in school but that the skill can be used in the context of their everyday activities. Exposure to Graphogame and other similar applications in their home environment may have helped parents and children to realise that reading is not a skill that is only acquired through formal structured learning, but it can be acquired even through unstructured playful activities and that it can be a source of fun. Further research is currently underway to explore ways of making this possible in rural communities with limited or no resources to support literacy acquisition for children and adults.

\section{Conclusion}

This study was prompted by the realisation that despite an increase in the rates of enrolment at rural primary schools, this increase has not resulted in corresponding increase in literacy rates in rural populations. This can be exemplified by the high number of rural children who are unable to meet basic literacy standards and the poor development of the control group in all literacy measurements in this research. The study has shown that Graphogame, used in the home environment, can be used as an instructional resource for initial literacy. Many rural families are beset with limited literacy resources and poor home literacy environments, and Graphogame and other literacy-enhancing technologies have the potential to act as resources for parents to provide the needed support to not only help the children with literacy acquisition but also equip them with basic literacy skills. It is, however, important to optimise home-school relationships to get the best out of the mixture of home, school and community language and literacy practices.

\section{Acknowledgements}

The authors would like to thank all the participants that made this study possible.

\section{Competing interests}

The authors declare that they have no financial or personal relationship(s) that may have inappropriately influenced them in writing this article.

\section{Authors' contributions}

The research and writing of this article was performed by J.C.N. and was supervised by R.S. The analysis of the results was supervised by J.W. (University of Jyvaskyla). 


\section{Funding information}

This research received no specific grant from any funding agency in the public, commercial, or not-for-profit sectors.

\section{Data availability statement}

Data sharing is not applicable to this article as no new data were created or analysed in this study.

\section{Disclaimer}

The views and opinions expressed in this article are those of the authors and do not necessarily reflect the official policy or position of any affiliated agency of the authors.

\section{References}

Africa Progress Panel, 2012, Seizing opportunities in times of global change. Africa progress report 2012: Jobs, justice and equity, Africa Progress Panel, Geneva, viewed 30 November 2012, from http://www.africaprogresspanel.org/en/ pressroom/press-kits/annual-report-2012/africa-progress-report-2012documents.

Aker, J.C., Ksoll, C. \& Lybbert, T.J., 2010, ABC, 123: The impact of a mobile phone literacy program on educational outcomes, CGD working Paper 223, Center for Global Development, Washington, DC.

Ball, J., 2011, Enhancing learning of children from diverse language backgrounds: Mother tongue-based bilingual or multilingual education in the early years, UNESCO \& Place de Fontenoy, University of Victoria, Paris.

Banda, D., 2012, A baseline assessment on grade 1 and 2 litercay skills in Petauke and Katete districts in the Eastern Province, Research report, Room to Read and UNICEF, University of Zambia, Lusaka.

Brombacher, A., Bulat, J., King, S., Kochetkova, E. \& Nordstrum, L., 2015, National assessment survey of learning achievement at grade 2: Results of early grade reading and mathematics in Zambia, RTI International, North Carolina.

Bruner, S., 1983, Child's talk, Cambridge University Press, Cambridge.

Bus, A.G., Van ljzendoorn, M.H. \& Pelligrini, A., 1995, 'Joint book reading makes for success in learning to read: A meta-analysis on intergenerational transmission of literacy', Review of Educational Research 65(1), 1-21. https://doi.org/ 10.3102/00346543065001001

Chansa-Kabali, T. \& Westerholm, J., 2014, 'The role of family on pathways to acquiring early reading skills in Lusaka's low-income communities', Human Technology: An Interdisciplinary Journal on Humans in ICT Environments 10(1), 5-21. https://doi. org/10.17011/ht/urn.201405281857

Chazan-Cohen, R., Raikes, H.P., Brooks-Gunn, J., Ayoub, C., Pan, B.A., Kisker, E.E. et al., 2009, 'Low-income children's school readiness: Parent contributions over the first five years', Early Education and Development 20(6), 958-997. https://doi. org/10.1080/10409280903362402

Chomsky, N., 1986, Knowledge of language: Its nature, origin and use, Praeger New York.

Clemensen, N., 2010, 'Teaching in a language limbo: Zambian primary teachers caught between policy and reality', in P. Culveleir, T. Du Plessis, M. Meeuwis, R. Vandekerckhove \& V. Webb (eds.), Multilingualism from below, pp. 35-50, Van Schaik Publishers, Pretoria.

Cole, M. \& Engestrom, Y., 1983, 'A cultural approach to distributed cognition', in G. Salomon (ed.), Distributed cognitions: Psychology and educational considerations, pp. 1-46, Cambridge University Press, Haifa.

Gutiérrez, K., 2002, 'Rethinking critical literacy in hard times: Critical literacy as transformative social practice', paper presented at the annual meeting of the National Council of Teachers of English, Atlanta, GA.

Holm, S., 1979, 'A simple sequentially rejective multiple test procedure', Scandinavian Journal of Statistics 62(2), 65-70.
Jere-Folotiya, J., Chansa-Kabali, T., Munachaka, J.C., Sampa, F., Yalukanda, C., Westerholm, J. et al., 2014, 'The effect of using a mobile literacy game to improve literacy levels of grade one students in Zambian schools', Educational Technology Research and grade one students in Zambian schools', Educational Technology Rese
Development 62(4), 417-436. https://doi.org/10.1007/s11423-014-9342-9

Jung, E., 2016, 'The development of reading skills in kindergarten influence of parental beliefs about school readiness, family activities, and children's attitudes to school' International Journal of Early Childhood 48(1), 61-78. https://doi.org/10.1007/ s13158-016-0156-2

Kalanje, E.S., 2011, Identifying first graders at risk of reading and writing difficulties: Creating a group-based screening tool in Kiswahili in Tanzania, University Press, Åbo.

Lyytinen, H., Erskine, J., Ahonen, T., Aro, M., Eklund, K., Guttorm, T. et al., 2008, 'Early identification and prevention of dyslexia: Results from a prospective follow-up study of children at familial risk for dyslexia', in G. Reid, A. Fawcett, F. Manis \& L. Siegel (eds.), The SAGE handbook of dyslexia, pp. 121-146, Sage, London.

Matafwali, B., 2010, 'The role of oral language in the acquisition of early literacy skills: A case of Zambian languages and English', PhD thesis, University of Zambia, Lusaka.

Meyers, L.S., Gamst, G. \& Guarino, A., 2006, Applied multivariate research: Design and interpretation, Sage, Thousand Oaks, CA.

Ministry of Education, Science, Vocational Training and Early Education (MESVTEE), 2013, National literacy framework, Curriculum Development Centre, Lusaka.

Ojanen, E., 2007, 'Sewero La-ma-u - A phonetic approach to literacy teaching in Zambia', Unpublished master's thesis, Dept. of Psychology, University of Jyväskylä, Jyväskylä.

Ojanen, E., Ronimus, M., Ahonen, T., Chansa-Kabali, T., February, P., Jere-Folotiya, J. et al., 2015, 'GraphoGame - A catalyst for multi-level promotion of literacy in diverse contexts', Frontiers in Psychology 6, 671. https://doi.org/10.3389/fpsyg.2015.00671

Salomon, G., 1993, 'No distribution without individuals' cognition: A dynamic interactional view', in G. Salomon (ed.), Distributed cognitions: Psychology and educational considerations, pp. 111-138, Cambridge University Press, Haifa.

Sampa, F.K., 2016, 'The outcomes of national literacy programs on basic reading skills in familiar language among Zambian early graders', Jyväskylä Studies in Education, Psychology and Social Research 560, p. 132.

Serpell, R., 1993, The significance of schooling: Life-journeys in an African society, Cambridge University Press, New York.

Serpell, R., 1997, 'Literacy connections between school and home: How should we evaluate them?', Journal of Literacy Research 29(4), 587-616. https://doi. org/10.1080/10862969709547975

Serpell, R., 2014, 'Promotion of literacy in sub-Saharan Africa: Goals and prospects of CAPOLSA at the University of Zambia', Human Technology 10(1), 23-39. https:// doi.org/10.17011/ht/urn.201405281858

Serpell, R., Baker, L. \& Sonnenschein, S., 2005, Becoming literate in the city: The Baltimore Early Childhood Project, Cambridge University Press, New York.

Snow, C., Burns, M. \& Griffin, P. (eds.), 1998, Preventing reading difficulties in young children, National Academy Press, Washington, DC.

Snow, C.E., Tabors, P.O. \& Dickinson, D.K., 2001, 'Language development in preschool years', in D.K. Dickinson \& P.O. Tabors (eds.), Beginning literacy with language: Young children learning at home and school, pp. 1-25, Brookes, Baltimore, MD.

Storch, S.A. \& Whitehurst, G.J., 2001, 'The role of family and home in the literacy development of children from low-income backgrounds', New directions for child and adolescent development 2001 (92), 53-72. https://doi.org/10.1002/cd.15

Street, B.V., 2003, 'What's "new" in new literacy studies? Critical approaches to literacy in and practice', Current Issues in Comparative Education 5(2), 77-91.

Tambulukani, G. \& Bus, A.G., 2012, 'Linguistic diversity: A contributory factor to reading problems in Zambian schools', Applied Linguistics 33(2), 1-21. https://doi. org/10.1093/applin/amr039

Timmons, K. \& Pelletier, J., 2015, 'Understanding the importance of parent learning in a school-based family literacy programme', Journal of Early Childhood Literacy 15(4), 510-532. https://doi.org/10.1177/1468798414552511

Van Steensel, R., 2006, 'Relations between socio-cultural factors, the home literacy environment and children's literacy development in the first years of primary education', Journal of Research in Reading 29(4), 367-382. https://doi org/10.1111/j.1467-9817.2006.00301.x

Weigel, D.J., Martin, S.S. \& Bennett, K.K., 2006, 'Contributions of the home literacy environment to preschool-aged children's emerging literacy and language skills', Early Child Development and Care 176(3-4), 357-378. https://doi.org/10.1080/ 03004430500063747

World Vision International, 2012, Annual review, World Vision, London. 